\title{
Outcome of Acute Burn Injuries in a Tertiary Care Centre of Kathmandu Nepal
}

\author{
Manish Devkota, Samit Sharma, Sangam Rayamajhi, Jayan M Shrestha, Ishwar Lohani \\ Department of Plastic Surgery and Burns, Maharajgunj Medical Campus, Tribhuvan University Teaching Hospital, \\ Institute of Medicine, Maharajgunj, Kathmandu, Nepal
}

\section{Corresponding author:}

Manish Devkota, MBBS, MS

Department of Plastic Surgery and Burns, Maharajgunj Medical Campus, Tribhuvan University Teaching Hospital, Institute of Medicine, Maharajgunj, Kathmandu, Nepal

Email:manish9sh@gmail.com

Submitted : Jun 5, 2020

Accepted : Jul 25, 2020

\begin{abstract}
Introduction

Burn injuries are associated with higher morbidity and mortality especially in middle and low-income countries. The objective of the study is to assess the outcome of acute burn injuries in a tertiary care center of Kathmandu, Nepal.
\end{abstract}

\section{Methods}

This is a descriptive cross-sectional study of the clinical data of acute burn patients admitted from January 2016-December 2018.

\section{Results}

Out of 124 patients with burn injuries, there were more females $(n=65,52.4 \%)$ than males $(n=59,47.6 \%)$. Flame burn was the most common mode of injury $(n=71,57.3 \%)$ followed by scald $(n=22,17.7 \%)$. Thirtyeight (30.6\%) patients arrived to hospital on the same day of injury. The average time required to reach our hospital was 24 hours. The most frequently involved site was lower extremities $(n=40,32.26 \%)$ followed by upper extremities ( $n=33,26.62 \%)$. Total body surface area (TBSA) involved in the burn injury ranges from $10 \%$ to $50 \%$ with a median of $15 \%$. Hospital stay was 14 to 58 days with a median of 17 days. Partial thickness burn was seen in 114 (91.94\%) patients whereas 10 (8.06\%) patients had full thickness burn. Surgical intervention was needed in 71 (57.26\%) patients. Among 71 patients, 12 patients underwent surgery twice. Fifty-two (41.94\%) patients were managed conservatively. The mortality rate was $4.03 \%$.

\section{Conclusion}

Adult female population is at high risk for burn injuries mostly due to flame burn. Delay in reaching care has also contributed for poor outcome of burn injuries. Majority of burn injury patients needed surgical intervention and hence improvement in surgical aspects can lead to better outcome of burn injuries.

Keywords: Acute burn, burn injury, burn outcome, epidemiology 


\section{INTRODUCTION}

$\mathrm{B}$ urn injuries are one of the public health issues accounting for estimated 265,000 deaths per year throughout the world, especially in low and middle- income countries. ${ }^{1,2}$ Treatment of burn injuries are problematic due to lack of expert human resources, expensive technologies and timely management. ${ }^{3}$ Globally, 11 million people sustain burn injuries causing significant morbidity and mortality with higher incidence in low and middle income countries (95\%). ${ }^{4}$ According to the Ministry of Health, Government of Nepal, 55,902 people sustain burn injuries every year. ${ }^{5} \mathrm{Nepal}$ is a developing country. Its literacy rate is $66 \% .{ }^{6}$ People are unaware about the consequences of burn injuries so they delay in seeking care. There is also delay in getting care due to lack of burn centers at various parts of Nepal. ${ }^{7}$ In addition, geographical barrier also plays a role in it. ${ }^{8}$ Burn injury varies in severity ranging from minor injuries requiring no treatment to severe injuries requiring intensive treatment. ${ }^{1}$ Burn injuries cause significant mortality and morbidities including physical disfigurement and post burn sequelae. ${ }^{9}$ There are various modes of burn injury, flame injury being the most common all over the world. ${ }^{10}$ Preventive care is the necessity to decrease mortality and morbidity. In Nepal, estimated deaths due to burn injury is 2100 per year. ${ }^{11}$ Five percent of disabilities are due to burn related injury in Nepal at all age group. ${ }^{12}$

To make a proper planning and strategy for the prevention of burn injury, actual epidemiological data is necessary. Lack of knowledge about the burden of burn patient and epidemiological data have become disadvantage to prevent burn injury.

High-income countries have become able to reduce burden of burn because of planning based on epidemiological data. ${ }^{1}$ But the same strategy cannot be applied to middle and low-income countries like Nepal. So, there arises the necessity of conducting research in our country regarding it. This study is designed to assess the outcomes of acute burn injuries in Tribhuvan University Teaching Hospital (TUTH), Maharajgunj, Kathmandu, Nepal.

\section{METHODS}

This study was retrospective cross-sectional study conducted by analyzing the clinical records of all the acute burn patients admitted to Tribhuvan University Teaching Hospital, Maharajgunj during the period of January 2016 to December 2018. The facility of burn injury treatment was started since establishment of TUTH, Maharajgunj and is currently supported by dedicated team of surgeons and nurses. This study included all forms of burn injuries of those $\geq 16$ years. Epidemiological data such as age, sex, mode of injury, causes, place of incident, mechanism of burn injury, circumstances, total body surface area
(TBSA) involved, depth, first aid treatment, time elapsed from the time of injury to the time of hospital arrival, existing comorbidities, surgical intervention done, days of hospital stay and complications during treatment, disposition and cause of death were noted. The TBSA burned was estimated by the rule of nine for all the patients. Ethical approval was obtained. Data from the proforma was entered and analyzed using the statistical package for social sciences (SPSS) for Windows version 16.

\section{RESULTS}

While reviewing the clinical records of all burn patients admitted during January 2016 to December 2018, 124 patients were admitted to our hospital. Sixty-five $(52.4 \%)$ of them were females and fiftynine $(47.6 \%)$ were males with female: male ratio 1.1:1. Age of the patients ranged from 17 to 93 years with the mean age of 32.38 years.

Flame burn was the leading cause for injury $(n=71$, $57.3 \%)$ followed by scald burn ( $n=22,17.7 \%)$. There were $24(19.4 \%)$ patients with electric burns. Chemical burn was seen in three patients $(2.4 \%)$. Four (3.2\%) patients had burn by other mechanisms like flash burn, contact burn, blast injury. Full thickness burn were present on lower and upper extremities in eight and two patients respectively.

Thirty-eight $(30.6 \%)$ patients were brought to our center on the same day of the injury. The average time required to reach our hospital after the incident was 24 hours which ranges from 1 hour to 60 days. Many patients had several areas of the body involved in the burn injury. The most frequently involved site was lower extremities ( $n=40,32.26 \%$ ) followed by upper extremities ( $n=33,26.62 \%)$. Areas involved are shown in Table 1.

Table 1. Sites of burn injury $(n=124)$

\begin{tabular}{lc}
\hline \multicolumn{1}{c}{ Site } & Number \\
\hline Lower Extremities & $40(32.26 \%)$ \\
Upper Extremities & $33(26.62 \%)$ \\
Head and Neck & $24(19.35 \%)$ \\
Chest & $12(9.68 \%)$ \\
Back & $8(6.45 \%)$ \\
Abdomen & $4(3.22 \%)$ \\
Perineum & $3(2.42 \%)$ \\
\hline
\end{tabular}

Co morbidity was present in 15 (12.09\%) patients. Chronic obstructive pulmonary disease was found in $3(2.4 \%)$ patients while upper respiratory tract infection and musculoskeletal injury were seen in five and seven patients respectively.

Only four patients (3.2\%) were reported to have inhalational injury. Total body surface area (TBSA) involved in the burn injury ranges from $10 \%$ to $50 \%$ 
Table 2. Total body surface involved $(n=124)$

\begin{tabular}{cc}
\hline $\begin{array}{c}\text { Total body surface area } \\
\text { (TBSA) }\end{array}$ & Number \\
\hline $0-20 \%$ & $97(78.22 \%)$ \\
$21-30 \%$ & $20(16.13 \%)$ \\
$31-40 \%$ & $5(4.03 \%)$ \\
$41-50 \%$ & $2(1.62 \%)$ \\
$51-60 \%$ & $0(0 \%)$ \\
$>60 \%$ & $0(0 \%)$ \\
\hline
\end{tabular}

with a median of $15 \%$. This is illustrated in Table 2 .

The time of hospital stay was 14 to 58 days with a mean of 20.43 days. Regarding the depth of injury, 114 (91.94\%) patients had partial thickness burn whereas 10 patients $(8.06 \%)$ had full thickness burn. On initial evaluation of patients with partial thickness burn 61 patients turn out to have second degree deep to third degree burn.

A total of $71(57.26 \%)$ patients underwent surgical intervention and one $(0.8 \%)$ patient denied for surgery. Among 70 patients, 12 patients underwent surgery twice. Fifty-two (41.94\%) were managed conservatively. Sixty patients underwent tangential excision and skin grafting and one patient underwent flap coverage.

Table 3. Types and number of surgery $(n=83)$

\begin{tabular}{lc}
\hline \multicolumn{1}{c}{ Site } & Number \\
\hline Escharotomy & $12(14.46 \%)$ \\
Burn Excision + Skin Grafting & $70(84.33 \%)$ \\
Flap & $1(1.21 \%)$ \\
\hline
\end{tabular}

Table 3 shows the distribution of different types and number of surgeries performed. Wound debridement and skin grafting was performed on 70 $(56.5 \%)$ patients. More than $90 \%$ graft was taken in all patients and no functional impairment was observed.

A total of $5(4.03 \%)$ patients died at the hospital. Causes of mortality were sepsis 4 (3.2\%) and respiratory tract infection $1(0.8 \%)$. Distribution of deaths according to TBSA is shown in Table 4.

Table 4. Mortality according to TBSA $(n=5)$

\begin{tabular}{cc}
\hline $\begin{array}{c}\text { Total body surface area } \\
\text { (TBSA) }\end{array}$ & Number \\
\hline $0-20 \%$ & 0 \\
$21-30 \%$ & 1 \\
$31-40 \%$ & 3 \\
$41-50 \%$ & 1 \\
$51-60 \%$ & 0 \\
$>60 \%$ & 0 \\
\hline
\end{tabular}

\section{DISCUSSION}

This study provides overall assessment of demographics, characteristics of burn injury and its related parameters of patients hospitalized with acute burn injuries at TUTH, Maharajgunj by reviewing charts of burn patients during two-year period. In the study, majority of patients (52.4\%) were females. In Nepalese society, women are involved in cooking and household activities. They wear loose flammable clothes like saree and shawls that can easily catch fire. Similar to our study, female predominance was seen in studies conducted by $B$ Karki, SM Rai, KK Nakarmi et al at Nepal cleft and burn center. ${ }^{2}$ Another study conducted by S Gupta, U Mohammad and S Gurung et al had same finding of female predominance as that of this study. ${ }^{8}$ A comparative study conducted by Lama et al concluded that women had more burn injuries than men. ${ }^{13}$ Female predominance in burn injuries was also seen in a study conducted by Laloe V. ${ }^{14}$ Karki $B$ et al in their study showed that female are more likely to get burn injuries than male..$^{15}$ Contrast result was seen in study conducted by Chalise et al. ${ }^{7}$

Patients who are more than 60 years are less likely to involve in both indoor and outdoor activities. But those less than 60 years are involved in both indoor and outdoor activities. So geriatric patients are less likely to get burn than younger people as shown by the study. Similar to this study results, a study conducted by SR Mashreky et al in Bangladesh has shown that with increasing age, burn injury decreases. ${ }^{16}$ In contrast to this study, older the age group, higher the risk of burn injury. ${ }^{3}$

Most common type of burn is due to flame and scald, which commonly occurs during indoor activities. The reason may be due to cloth catching on fire while doing puja or warming the new born babies in front of fire or self warming during winter seasons or involvement in household activities. This finding is consistent with study conducted by NP Sharma et al in a tertiary care center in Nepal where flame burn was most common mode of injury. ${ }^{10}$ Laloe conducted a two year prospective study in a hospital of Eastern Sri-Lanka which concluded that flame injury was most common mode of injury. ${ }^{14}$ Contrary to our report, a study showed that main type of burn in developed countries was scald. ${ }^{8}$

Approximately $30 \%$ of patients were able to visit our institution on the day of injury. Most of the burn patients were resident of outside the Kathmandu valley and only minority of them were of inside the valley. Because of geographical barrier, there was delay in reaching care.

Posterior aspect of lower extremities is predisposed to burn injury than upper extremities. Mostly they are due to flame injury. In contrast to this study, a retrospective study conducted by Rai SM et al at Nepal Cleft \& Burn Center, Kirtipur Hospital showed 
that upper extremity was the frequently involved site in burn injury. ${ }^{2}$ The mortality rate of burn patients was $4.03 \%$.

The limitation of this study is its small sample size and the inference obtained cannot be applied to the burn injuries with TBSA more than $50 \%$.

\section{CONCLUSION}

Outcome of acute burn injuries is poor and its management is challenging. Adult female population is at high risk. Flame injury was the most common mode of injury followed by scald and then electric burn. The most common site of injury was lower extremities. Delay in reaching care has also contributed in poor outcome of burn injuries. So, addressing this issue helps to improve the burn scenario in Nepal.

\section{CONFLICT OF INTEREST}

None declared.

\section{REFERENCES}

1. Tripathii S, Basnet SJ. Epidemiology of burn injuries in Nepal: a systemic review. Burns and Trauma. 2017 Dec 1;5:(1).

2. Rai $S M$, Karki $B, N a k a r m i ~ K$ et al. Retrospective study on early outcome of acute burn injuries treated at Nepal Cleft and Burn Centre of Public Health Concern Trust-Nepal. JNHRC. 2014 SepDec;12(28):195-9.

3. 3.Mashreky SR, Rahman A, Chowdhury SM et al. Non-fatal burn is a major cause of illness: findings from the largest communitybased national survey in Bangladesh. Injury prevention. 2009 Dec 1;15(6):397-402.

4. World Health Organisation. The global burden of disease: 2004 update. Available at: http://www.who.int/healthinfo/global_ burden_disease/2004_report_update/en/. Accessed November 3, 2019.

5. Department of Health Services. Annual Report 2008-9. Ministry of Health and Population, GoN; Kathmandu, Nepal in 2010.

6. Central Bureau of Statistics (Nepal). National Population and Housing Census 2011 (National Report). Kathmandu, Nepal: National Planning Commission Secretariat, Government of Nepal. http://cbs.gov. np/?p=2017. Published 2012. Accessed November 3, 2019.

7. Chalise PR, Shrestha S, Sherpa $K$ et al. Epidemiological and bacteriological profile of burn patients at Nepal Medical College Teaching Hospital. Nepal Med Coll J. 2008 Dec;10(4):233-7.

8. Gupta S, Mahmood U, Gurung $S$ et al. Burns in Nepal: a population based national assessment. Burns. 2015 Aug 1;41(5):1126-32.

9. Peck MD. Epidemiology of burns throughout the world. Part I: Distribution and risk factors. Burns. 2011 Nov 1;37(7):1087-100.

10. Sharma NP, Duke JM, Lama BB et al. Descriptive epidemiology of unintentional burn injuries admitted to a tertiary-level government hospital in Nepal: gender-specific patterns. Asia Pac J Public Health. 2015; 27 (5): 551-60.

11. Bhandari SB, Sah SK, Bhandari KB et al. Perception and Practice among Community People and Health Service Providers on Care and Management of Burn Injuries in Nepal: A Qualitative Study. Journal of Nepal Health Research Council. 2019 Dec 13;17(3):3159.

12. World Health Organisation Media Center Fact Sheets: Burns. 2018. Available at: http://www.who.int/mediacentre/factsheets/fs365/ en/.

13. Lama BB, Duke JM, Sharma NP et al. Intentional burns in Nepal: A comparative study. J Burns. 2015 Sep 1;41(6):1306-14.

14. Laloe V. Epidemiology and mortality of burns in a general hospital of Eastern Sri Lanka. Burns. 2002 Dec 1;28(8):778-81.

15. Karki B, Rai MS, Nakarmi KK et al. Clinical Epidemiology of Acute Burn Injuries at Nepal Cleft and Burn Centre, Kathmandu, Nepal. Annals of Plastic Surgery. 2018 Mar; 80(3):S95-97.

16. Golshan A, Patel C, Hyder AA. A systematic review of the epidemiology of unintentional burn injuries in South Asia. Journal of public health. 2013 Sep 1;35(3):384-96. 